\title{
Responsibility to Protect dalam Kasus Genosida oleh ISIL terhadap Yazidi-Irak melalui Intervensi Militer Amerika Serikat
}

\author{
Dewi Agha Putri, Hasan Sidik \\ Program Studi Hubungan Internasional, Fakultas IImu Sosial dan IImu Politik \\ Universitas Padjadjaran \\ e-mail: dewiagha1@gmail.com
}

\begin{abstract}
Abstrack
This article aims to explain the military intervention carried out by the United States in response to the genocide carried out by the Islamic State of Iraq and the Levant (ISIL) against Yazidi community in Iraq. The researchers use the concept of Responsibility to Protect (R2P), which refers to a report from the International Commission on Intervention and State Sovereignty to see the procedure for procuring military intervention in the R2P framework in detail. This article found that besides several collateral damages, military intervention carried out by the United States was following the procedures set out by the International Commission on Intervention and State Sovereignty. The United States' intervention was done by the Iraqi government's approval, which had previously requested assistance from the United States. This intervention can be seen as Iraqi collective self-defense as stated in Article 51 of the Charter of the United Nations or intervention based on approval as stipulated in Article 20 of the Responsibility of States for International Wrongful Acts 2001. This research was conducted qualitatively using sources in the form of a variety of documents and mass media reports.
\end{abstract}

Keywords: collective self-defense, Responsibility to Protect, US military intervention, Yazidigenocide

\section{Abstrak}

Artikel ini bertujuan untuk menjelaskan intervensi militer yang dilakukan oleh Amerika Serikat (AS) dalam menanggapi genosida yang dilakukan oleh Islamic 
State of Iraq and the Levant (ISIL) terhadap komunitas Yazidi di Irak. Peneliti menggunakan konsep Responsibility to Protect (R2P), yang merujuk pada laporan dari the International Commission on Intervention and State Sovereignty (ICISS) untuk melihat prosedur intervensi militer dalam kerangka kerja R2P secara terperinci. Artikel ini menemukan bahwa meskipun telah terjadi sejumlah dampak sampingan (collateral damages), intervensi militer yang dilakukan oleh AS mengikuti prosedur yang ditetapkan oleh ICISS, antara lain, dilakukan AS atas persetujuan pemerintah Irak yang sebelumnya meminta bantuan dari AS. Intervensi ini dapat dilihat sebagai pertahanan diri kolektif Irak sebagaimana tercantum dalam Piagam Perserikatan Bangsa-Bangsa Pasal 51 atau intervensi berdasarkan persetujuan sebagaimana diatur dalam Pasal 20 Responsibility of States for International Wrongful Acts tahun 2001. Penelitian ini dilakukan secara kualitatif dengan menggunakan sumber-sumber berupa berbagai dokumen dan laporan media massa.

Kata Kunci: genosida Yazidi, intervensi militer, pertahanan diri kolektif, Responsibility to Protect

\section{Pendahuluan}

Pada Agustus 2014, telah terjadi penyerangan besar-besaran yang terjadi di wilayah Sinjar, Irak, yang dilakukan oleh Islamic State of Iraq and the Levant (ISIL) terhadap komunitas Yazidi. ISIL merupakan sebuah kelompok teroris yang berpusat di Irak dan Suriah namun juga sering melakukan berbagai penyerangan di negaranegara lain. Misalnya, sepanjang bulan Januari tahun 2016, ISIL melakukan serangan di Libya, Turki, Arab Saudi, dan Indonesia (kasus bom Sarinah). Basis ideologi ISIL dan kelompok teror yang mengatasnamakan Islam lainnya adalah takfirisme, yaitu memandang bahwa orang-orang lain, selain yang masuk ke dalam kelompoknya, sebagai kafir atau murtaddin (orang-orang murtad). Berdasarkan interpretasi sepihak mereka atas yuridis Islam, orang-orang 'kafir' tersebut dipandang boleh untuk dianiaya, dijarah, atau bahkan dibunuh (Muhdhor, 2017).

Sementara itu, Yazidi merupakan sebuah kelompok etno-religius yang berpusat di Provinsi Ninewa dan Dohuk. Sebagian besar dari mereka menetap di Sinjar, Irak Utara. Orang-orang Yazidi ini sebenarnya beretnis Kurdi. Akan tetapi, tidak seperti mayoritas orang Kurdi, mereka tidak memeluk agama Islam. Mereka percaya kepada "Xweda" yang berarti 'sesuatu' yang menciptakan mereka, yang mereka anggap sebagai satu-satunya Tuhan. Pada dasarnya, kepercayaan Yazidi ini 
berisikan gabungan antara elemen Kristiani, Islam, Zoroastrianisme, dan agamaagama pro-Abrahamik Mesopotamia. Yang menjadikan kepercayaan Yazidi ini unik adalah mereka percaya terhadap "Melek Tawus" yang digambarkan sebagai Dewi Burung Merak yang bajik dan merupakan pelindung bagi mereka. Oleh sebab itulah kemudian Yazidi ini sering kali dianggap sebagai orang 'musyrik' atau bahkan 'penyembah setan' (Zoonen dan Wirya, 2017).

Tanggal 3 Agustus 2014, ISIL dilaporkan masuk ke Sinjar melalui Mosul dan Tel Affar, lalu melancarkan serangan kepada kaum Yazidi secara tiba-tiba. Pada saat itu, orang-orang Yazidi memiliki perlindungan yang sangat terbatas. Yang bisa mereka lakukan adalah lari menyelamatkan diri ke Gunung Sinjar dalam kondisi yang sangat berat, yaitu musim panas dengan suhu di atas 50 derajat Celcius, tanpa perbekalan makanan, minuman, dan pakaian yang cukup. Diperkirakan ratusan orang tewas dalam perjalanan menuju Gunung Sinjar, dan sebagian diculik oleh ISIL. Selama mereka berlindung di Gunung Sinjar ini, ratusan orang meninggal, termasuk bayi dan anak-anak (Human Rights Council, 2016).

Dalam penyerangan tersebut, ISIL telah melakukan berbagai tindakan yang dikategorikan melanggar HAM internasional. Berdasarkan laporan yang diterbitkan oleh United Nations Human Rights Office of the High Commissioner (OHCHR) dan United Nations Assistance Mission for Iraq (UNAMI), ISIL pada saat itu telah melakukan pembunuhan massal, pemaksaan pindah agama, kejahatan seksual, perbudakan seksual, kerja paksa, dan tindakan lainnya. Dengan berbagai tindakan tersebut, penyerangan ISIL telah menimbulkan banyak korban jiwa. Juga dilaporkan bahwa setidaknya, hingga saat ini, terdapat 3.200 orang Yazidi yang belum ditemukan atau masih menjadi tawanan ISIL (Webb, 2018).

Kasus penyerangan ini mendapatkan perhatian internasional. Pada tanggal 8 Agustus, setelah dilakukan sidang darurat Dewan Keamanan PBB, dan atas permintaan pemerintah Irak, AS memulai pemberian bantuan melalui pesawat (airdrops) kepada warga sipil yang terjebak di Gunung Sinjar, lalu diikuti dengan pemberian bantuan oleh Inggris, Perancis, dan Australia pada hari-hari berikutnya. AS juga melakukan serangan udara untuk menghentikan pergerakan ISIL di kawasan Sinjar dan Erbil. Pada 14 Agustus, militer AS melakukan serangkaian serangan udara untuk membantu milisi Kurdi (YPG) untuk membuka koridor evakuasi di Gunung Sinjar sehingga puluhan ribu warga yang terjebak di sana bisa keluar. Pada tanggal 16 Agustus, AS kembali melakukan serangan udara terhadap ISIS di bendungan Mosul, sehingga tentara Irak dan milisi Kurdi bisa menguasai kembali bendungan tersebut (UNAMI and OHCHR Report, 2014). 
Intervensi militer terhadap ISIS dilakukan oleh AS dalam kerangka responsibility to protect (R2P). Pada dasarnya, R2P ini berangkat dari gagasan bahwa setiap negara memiliki tanggung jawab untuk melindungi populasinya dari pelanggaran hak asasi manusia, terutama pelanggaran-pelanggaran yang menimbulkan korban jiwa massal, seperti genosida. Oleh sebab itu, sebuah negara yang berdaulat sebenarnya memegang tanggung jawab primer di dalam R2P ini. Hanya saja, ketika negara tersebut terbukti tidak mampu atau gagal untuk melindungi warganya, prinsip perlindungan ini jatuh kepada komunitas internasional. Dengan kata lain, ketika negara tidak mampu melindungi masyarakatnya, maka komunitas internasional memiliki justifikasi untuk masuk dan melakukan intervensi dengan tujuan untuk menghindari atau mengakhiri penderitaan warga di wilayah negara tersebut.

Dalam kasus ini, Irak sebagai negara tempat di mana Yazidi tinggal, menjadi pihak yang memiliki tanggung jawab primer untuk melindungi Yazidi dari genosida yang dilakukan oleh ISIL. Berkaitan dengan hal tersebut, Irak sendiri pada dasarnya telah berupaya untuk melindungi Yazidi dengan cara mengerahkan pasukan militernya, yaitu Iraqi Armed Forces bekerja sama dengan Peshmerga yang merupakan pasukan milik Pemerintah Kurdistan untuk melindungi Yazidi dan membukakan koridor bagi mereka untuk keluar dari Gunung Sinjar ke wilayah Suriah. Namun, menyadari bahwa rendahnya kemampuan untuk melindungi Yazidi, Pemerintah Irak kemudian meminta bantuan kepada Amerika Serikat.

Setelah serangan militer bulan Agustus 2014, AS kemudian membentuk The Global Coalition against Daesh (selanjutnya disebut 'Koalisi'), tepatnya pada bulan September 2014. Koalisi yang bertujuan untuk melawan Daesh atau ISIL ini terdiri dari 82 negara, antara lain AS, Inggris, NATO, Perancis, Selandia Baru, Belanda, Australia, Arab Saudi, Turki, dan lain-lain. Selain melakukan operasi militer melawan ISIL di Irak dan Suriah, Koalisi juga berkomitmen untuk menghentikan aliran finansial $I S I L$, mencegah masuknya milisi teroris asing melintasi perbatasan, mendukung stabilisasi dan pemulihan layanan publik yang penting di daerah-daerah yang telah dibebaskan dari ISIL, dan melawan propaganda ISIL (theglobalcoalition.org).

Selama 1 tahun (Agustus 2014-Agustus 2015), AS telah melakukan 5700 serangan bom terhadap target-target ISIL. Dalam serangan ini, terjadi collateral damage atau dampak sampingan, di mana ada ratusan warga sipil tewas. Dalam laporan yang dirilis oleh Airwars, sebuah proyek investigasi yang dilakukan sejumlah jurnalis independen, dalam serangan AS tersebut minimalnya 459 warga sipil tewas, termasuk di antaranya 100 lebih anak-anak (Ross, 2015). 
Penulis merujuk kepada beberapa penelitian terdahulu yang membahas isu ini, antara lain Kizilhan (2017), membahas mengenai berbagai kejahatan kemanusiaan yang dihadapi oleh komunitas Yazidi, termasuk serangan ISIL tahun 2014. Smith (2017) membahas mengenai sejarah terbentuknya ISIL; Mitrani (2017) membahas mengenai kemampuan negara-negara untuk memegang nilai-nilai dan standarstandar dalam mengerahkan kapasitas untuk bertindak dalam arena internasional dengan tata krama kolektif untuk tujuan kolektif; dan Sliney (2015) yang mengkaji basis hukum serangan AS dalam menyerang ISIL di Irak dan Suriah.

Dalam penelitian ini, penulis berusaha memperdalam kajian yang telah dilakukan sebelumnya, terutama dikaitkan dengan collateral damage yang terjadi. Penulis akan membahas intervensi militer AS di Irak, khususnya dalam melawan ISIS yang telah melakukan genosida terhadap komunitas Yazidi di Sinjar, dengan menggunakan kerangka R2P. Penulis akan meneliti apakah serangan itu sudah memenuhi persyaratan bagi implementasi R2P berdasarkan kepada apa yang terkandung di dalam Piagam PBB dan International Commission on Intervention and State Sovereignty (ICISS) yang menjadi landasan dasar bagi R2P, serta apa dampak dari intervensi tersebut. Dalam paparan selanjutnya, kajian ini akan diuraikan dalam tiga pokok bahasan, yaitu penjelasan mengenai landasan hukum R2P, genosida yang dilakukan ISIL terhadap komunitas Yazidi Irak, dan intervensi AS dalam kerangka R2P.

\section{Responsibility to Protect (R2P)}

Konsep R2P diperkenalkan dalam laporan studi yang dikeluarkan oleh International Comission on Intervention and State Sovereignty (ICISS) yang berasal dari pemerintah Kanada. Laporan tersebut berisikan prinsip, norma, aturan, dan prosedur dari pelaksanaan R2P. Di dalamnya disebutkan bahwa aktor yang memiliki otoritas tertinggi dari pelaksanaan R2P ini adalah negara, namun otoritas tersebut dapat diserahkan kepada komunitas internasional yang berdasarkan kepada aturan yang terkandung di dalam Piagam PBB atau berdasarkan otoritas PBB melalui Dewan Keamanan PBB. Penyusunan laporan ini bertujuan untuk dijadikan landasan dalam pelaksanaan R2P. Laporan tersebut kemudian dipresentasikan pada 18 Desember 2001 oleh Sekjen Perserikatan Bangsa-Bangsa (PBB), Kofi Annan. Dalam laporan tersebut dinyatakan bahwa:

Ketika sebuah populasi menderita bahaya yang serius, seperti hasil dari perang internal, insurgensi, represi atau kegagalan negara, dan negara tidak menghendaki atau tidak mampu untuk menghentikan atau menghindarinya, 
prinsip non-intervensi diberikan kepada responsibility to protect internasional (Breau, 2016: 20).

Berdasarkan pernyataan tersebut, dapat dikatakan bahwa komunitas internasional memiliki hak untuk melakukan intervensi atas nama kemanusiaan, yaitu dalam kerangka R2P ketika negara yang bersangkutan tidak mampu untuk menghentikan atau menghindari populasinya dari penderitaan. Selanjutnya, Dewan Kemanan PBB dalam Pertemuan Tingkat Tinggi (high-level UN World Summit meeting) tahun 2005 memformulasi dan mengadaptasi prinsip-prinsip mengenai R2P yang merujuk kepada konsep yang berasal dari ICISS, tepatnya dalam paragraf 138 dan 139 dari Dokumen Hasil Pertemuan Dunia (World Summit Outcome Document) tahun 2005.

R2P memiliki tiga tahapan, yaitu sebagai berikut.

\section{Responsibility to prevent}

Tahap ini bertujuan untuk mengatasi akar dan penyebab dari adanya konflik internal atau krisis kemanusiaan yang membahayakan populasi. Elemen ini merupakan tanggung jawab yang paling utama bagi negara yang berdaulat. Upaya perlindungan populasi dari krisis kemanusiaan tidak terbatas kepada upaya nasional, namun juga melibatkan upaya dan dukungan dari komunitas internasional. Dukungan tersebut dapat berbentuk penyediaan bantuan bagi inisiatif lokal untuk meningkatkan pemerintahan yang baik, penegakan HAM dan aturan hukum, serta upaya mediasi atau rekonsiliasi (ICISS, 2001).

\section{Responsibility to react}

Tahapan ini mencakup semua tindakan yang merupakan reaksi dari situasi yang membutuhkan perlindungan, mencakup tindakan koersif seperti sanksi-sanki politik, ekonomi atau yudisial, dan dalam kasus-kasus ekstrim dapat mencakup intervensi militer. Intervensi militer hanya dapat dilakukan ketika terdapat konflik sipil dan represi yang bersifat sangat keras yang mengancam kelangsungkan hidup warga sipil, seperti adanya pembunuhan massal, genosida atau pembunuhan etnis dalam skala besar. Prinsip non-intervensi dapat dikesampingkan ketika terjadi kekerasan yang "mengejutkan hati nurani manusia", atau yang menunjukkan bahaya yang jelas bagi keamanan internasional, yang mengharuskan penggunaan intervensi militer koersif. 
Untuk melakukan intervensi militer, ada enam kriteria yang harus dipenuhi, yaitu right authority, just cause, right intention, last resort, proportional means and reasonable prospects. Right authority mengarah kepada otoritas yang berhak untuk melakukan intervensi. Right intention mengarah kepada tujuan primer dari intervensi tersebut, yaitu untuk menghentikan atau menghindari penderitaan manusia. Just cause mengarah kepada hal-hal yang dapat menjustifikasi pengadaan intervensi, seperti adanya kehilangan jiwa dalam skala besar dan pemusnahan etnis skala besar. Last resort mengartikan bahwa intervensi militer hanya dapat dilakukan jika upaya pencegahan gagal dilakukan dan satu-satunya jalan yang tersedia hanya intervensi militer. Proportional means mengartikan harus adanya perencanaan skala dan durasi intervensi militer; dan serangan dilakukan dengan intensitas minimum sejauh yang diperlukan untuk menyelamatkan kemanusiaan yang menjadi target. Kemudian, reasonable prospects mengartikan bahwa intervensi militer hanya dapat dijustifikasi jika hal tersebut memiliki peluang yang masuk akal untuk menghentikan atau menghindari penderitaan (ICISS, 2001).

\section{Responsibility to rebuild}

Tahap ini dilakukan pasca dilakukannya intervensi militer; terdiri dari peace building (upaya rekonstruksi dan rehabilitasi), security (penyediaan keamanan dan perlindungan dasar bagi populasi), justice and reconciliation (penegakan keadilan dan dilakukannya proses rekonsiliasi), dan development (pertumbuhan ekonomi, pembuatan kembali pasar-pasar dan pembangunan yang berkelanjutan melalui proyek-proyek yang melibatkan kerjasama antara lembaga nasional dan internasional) (ICISS, 2001).

Berdasarkan hukum internasional, ada tiga kondisi dilakukannya R2P, yaitu, (1) consent, yakni adanya izin dari negara yang menjadi target R2P, hal ini berdasarkan Piagam PBB pasal 2 poin 7 dan ARSIWA (Responsibility of States for Internationally Wrongful Acts) tahun 2001 pasal 20; (2) wewenang Dewan Keamanan PBB, yakni otorisasi R2P harus berada di tangan PBB karena sesuai dengan tanggung jawabnya untuk menjaga perdamaian dan keamanan internasional, sebagaimana tercantum dalam Piagam PBB pasal 24; (3) dilakukan jika telah ada serangan bersenjata yang mengancam keselamatan populasi, berdasarkan Piagam PBB pasal 51.

Berdasarkan Pasal 51 tersebut, intervensi militer dapat dilakukan dengan landasan pertahanan diri, baik individu maupun kolektif jika terjadi serangan bersenjata. Pertahanan diri suatu negara dapat dilakukan dengan cara meminta bantuan kepada negara lain untuk mengatasi atau menghindari krisis yang memberikan penderitaan 


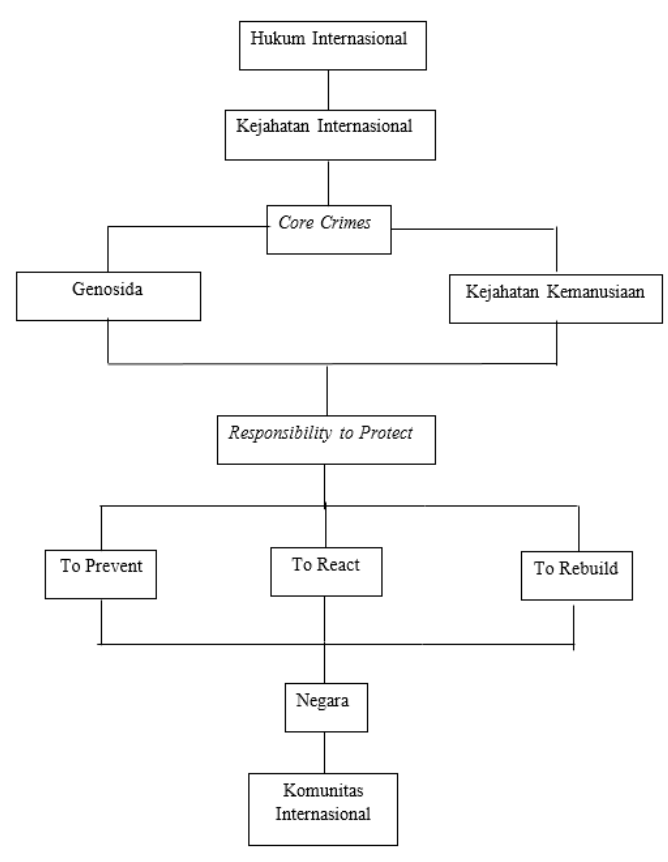

bagi manusia. Dengan demikian, suatu negara yang dimintai bantuan dapat melakukan intervensi militer sebagai bentuk dari pertahanan diri kolektif.

Berikut ini bagan yang merangkum struktur dan landasan hukum pelaksanaan $\mathrm{R} 2 \mathrm{P}$.

\section{Genosida yang Dilakukan ISIL terhadap Komunitas Yazidi di Irak}

Tindak penyerangan yang dilakukan oleh ISIL terhadap komunitas Yazidi termasuk kategori genosida berdasarkan Pasal II Konvensi Genosida 1948 dan

Pasal 6 Statuta Roma. Menurut kedua instrumen hukum tersebut, genosida memiliki definisi segala tindakan yang dilakukan dengan niat untuk menghancurkan, seluruh atau sebagian, kelompok bangsa, etnis, ras, atau agama (International Criminal Court, 2011). Suatu tindakan berdasarkan pada pasal-pasal tersebut dapat dikatakan sebagai genosida hanya ketika targetnya merupakan kelompok yang dilindungi (protected groups). Selain itu, yang membedakan genosida dengan kejahatankejahatan lainnya yang tercakup di dalam Statuta Roma adalah adanya niat khusus untuk menghancurkan sebagian atau seluruh kelompok yang dilindungi.

Komunitas Yazidi merupakan kelompok etno-religius yang secara agama maupun etnis dilindungi. ISIL menyerang komunitas Yazidi didasari ideologi bahwa komunitas tersebut 'kaum kafir'. Dengan kata lain, penargetan Yazidi oleh ISIL sangat terkait dengan agamanya dan Yazidi sendiri adalah sebuah komunitas khusus. Pada dasarnya, hukum yang mengatur mengenai genosida ini terdiri dari lima jenis dan kelima jenis kejahatan itu dilakukan oleh ISIL, yaitu sebagai berikut.

\section{Membunuh anggota-anggota kelompok}

ISIL telah terbukti melakukan pembunuhan atas anggota Yazidi, di mana ratusan laki-laki dewasa ditembak akibat menolak untuk berpindah agama. Selain itu, ISIL juga telah membunuh anak-anak yang mencoba untuk melarikan diri ketika para tentara ISIL telah membeli wanita dan anak-anak Yazidi dan dipindahkan ke 
Suriah. Banyak dari wanita dan anak-anak yang ditangkap ISIL melakukan bunuh diri sebelum diperjualbelikan oleh ISIL. Hal tersebut merujuk kepada yurisprudensi International Criminal Tribunal for The Former Yugoslavia (ICTY) dapat dikategorikan sebagai pembunuhan karena ISIL dalam hal ini telah menempatkan wanita dan anakanak tersebut ke dalam kondisi yang mendorong mereka untuk bunuh diri (Human Rights Council, 2016).

\section{Menyebabkan kerugian badan dan mental yang serius dari anggota kelompok}

Tindak penyerangan ISIL yang mencakup penyiksaan, pemerkosaan, kejahatan seksual atau perlakuan yang tidak manusiawi dan merendahkan derajat telah menghancurkan fisik dan psikologis dari orang-orang Yazidi. Wanita dan anak perempuan yang menjadi korban perbudakan mendapatkan banyak tindak kekerasan, termasuk harus melihat ibunya terbunuh, diperkosa secara berkelompok, pemerkosaan, dan pemukulan. Selain itu, mereka juga sering kali dipaksa untuk bekerja sebagai budak bagi tentara ISIL dan keluarganya. Dalam hal ini, wanita dan perempuan Yazidi tidak diakui derajatnya sebagai manusia dan dianggap sebagai 'kafir kotor' (Human Rights Council, 2016).

\section{Sengaja menimbulkan kondisi kehidupan kelompok yang ditujukan untuk menyebabkan kehancuran fisik baik secara keseluruhan atau sebagian}

Elemen ini mengarah kepada tindakan yang dilakukan untuk menghancurkan kelompok dengan cara merampas kebebasan atau sumber daya yang berguna untuk kelangsungan hidup, sepeti makanan, air, layanan kesehatan, dan sumber daya lainnya. Dalam kasus ini, ISIL dengan sengaja membatasi suplai sumber kehidupan kaum Yazidi, yang mencakup suplai makanan, air, dan layanan kesehatan, terutama ketika orang-orang Yazidi sedang berlindung di Gunung Sinjar. Orang-orang yang mengungsi tersebut harus bertahan hidup dengan minim air dan makanan, di bawah suhu yang sangat panas, melebihi 50 derajat celsius. Lebih dari itu, para tentara ISIL mencoba untuk menyerang pesawat dan helikopter yang datang membawa pasokan makanan untuk para pengungsi Yazidi.

Orang-orang Yazidi yang berada dalam kondisi perbudakan seksual juga menerima suplai makanan dan minuman yang sedikit, tidak menerima layanan kesehatan, dan mengalami tindak kekerasan. Berdasarkan yurisprudensi 
International Criminal Tribunal for Rwanda (ICTR), tindakan yang dilakukan oleh ISIL tersebut merupakan sebuah metode untuk menghancurkan Yazidi yang secara tidak langsung menyebabkan kematian anggota kelompok (Human Rights Council, 2016).

\section{Menerapkan tindakan yang dimaksudkan untuk mencegah kelahiran dalam kelompok}

Selama penyerangan berlangsung, ISIL telah berupaya untuk mencegah kelahiran melalui pemerkosaan, mutilasi seksual, sterilisasi, konsumsi obat pengontrol kehamilan secara paksa, pemisahan laki-laki dan perempuan, melarang pernihakan, menghamili wanita Yazidi, dan menyebabkan trauma mental. Selain itu, tentara ISIL juga membunuh laki-laki Yazidi yang menjadi salah satu cara untuk mencegah kelahiran di dalam kelompok tersebut. ISIL juga memaksa orang-orang Yazidi untuk pindah agama karena dalam agama Yazidi, orang tua dari anak Yazidi haruslah beragama Yazidi, sehingga ketika mereka pindah agama menjadi Muslim mereka tidak bisa menikah.

Lebih dari itu, ISIL juga berupaya untuk mencegah kelahiran dengan cara pemerkosaan, yang menyebabkan trauma yang pada akhirnya menyebabkan wanita tersebut menjadi depresi dan tidak dapat bereproduksi. Dengan adanya pemerkosaan yang dilakukan terus-menerus, wanita dan anak perempuan Yazidi mengalami kegelisahan seksual dan merasa kehilangan kehormatannya (Human Rights Council, 2016).

\section{Pemindahan paksa anak-anak kelompok tersebut ke kelompok lain}

Dalam penyerangan ini, ISIL memindahkan anak-anak Yazidi melalui dua cara, yaitu anak perempuan yang berusia 9 tahun ke atas akan diambil dari ibunya dan dijual sebagai budak seks dan anak laki-laki yang berusia 7 tahun ke atas akan dibawa oleh ISIL untuk dilatih menjadi tentara ISIL di Suriah dan Irak. Dengan demikian, terjadi pemaksaan ideologi terhadap anak-anak Yazidi (Human Rights Council, 2016).

\section{Pelaksanaan Responsibility to Protect AS dan Komunitas Internasional}

\section{Responsibility to React}

Dalam kasus kejahatan internasional yang dilakukan oleh ISIL terhadap komunitas Yazidi di Irak, tahapan pertama R2P, yaitu responsibility to prevent gagal dilakukan. Responsibility to prevent mengarah kepada upaya nasional, yaitu Irak; dan 
internasional, yaitu komunitas internasional untuk mencegah serangan ISIL yang mendatangkan penderitaan terhadap komunitas Yazidi. Upaya pencegahan tersebut dapat berbentuk mempromosikan hak komunitas Yazidi untuk mendapatkan perlindungan dari Pemerintah Irak, terlebih komunitas Yazidi tersebut merupakan kaum minoritas di Irak. Namun, kenyataannya, pada saat itu responsibility to prevent ini tidak terimplementasikan dengan maksimal, yang mana pada akhirnya komunitas Yazidi tidak terhindarkan dari penyerangan ISIL.

Dalam kasus kejahatan internasional yang dilakukan oleh ISIL terhadap komunitas Yazidi di Irak, responsibility to react dilakukan berdasarkan kepada prinsip self-defence yang tertuang dalam Pasal 51 Piagam PBB. Dalam kasus ini, Irak sebagai negara yang berdaulat dan merupakan aktor utama yang memiliki tanggung jawab atas komunitas internasional memiliki kewajiban untuk melindungi warga negaranya, yang mana kemudian Irak menggunakan haknya atas self-defence untuk meminta bantuan kepada komunitas internasional, yaitu seperti kepada Amerika Serikat dan adanya pengerahan Global Coalition to Defeat ISIL di Irak dan Suriah yang dipimpin oleh AS. Implementasi responsibility to react dalam kasus ini dapat dijustifikasi karena kasus ini merupakan kasus ekstrim, yang mana terdapat kehilangan nyawa dalam skala besar melalui pembunuhan massal dan pemusnahan etnis yang mengejutkan hati nurani manusia.

AS merupakan salah satu aktor dari komunitas internasional yang paling aktif dalam merespon tindak kejahatan internasional yang dilakukan oleh ISIL terhadap komunitas Yazidi di Irak pada saat itu. Dalam kasus tersebut, AS meyakini bahwa tindak penyerangan yang dilakukan oleh ISIL terhadap Yazidi merupakan sebuh genosida, sebagaimana terlihat dalam pidato Presiden Obama pada tanggal 7 Agustus 2014:

"In recent days, Yezidi women, men and children from the area of Sinjar have fled for their lives. And thousand - perhaps tens of thousands - are now hiding high up on the mountain, with little but the clothes on their backs. They're without food; they're without water. People are starving. And children are dying of thirst. Meanwhile, ISIL forces below have called for the systematic destruction of the entire Yezidi people, which would constitute genocide. So these innnocent slaughteres, or stay and slowly die of thirst and hunger" (Jones, 2015).

Dalam merespon genosida tersebut, AS sebagai bagian dari komunitas internasional telah melancarkan intervensi militer yang dimulai dengan pemberian serangan udara sejak tanggal 9 sampai tanggal 13 Agustus 2014. Pada tanggal 9 
Agustus 2014, AS melancarkan serangan udara dengan mengerahkan kombinasi pesawat berawak dan tak berawak dan berhasil menghancurkan empat Armed Personnel Carriers (APCs) ISIL yang menembaki non-combatant Yazidi tanpa pandang bulu. Pada 11 Agustus 2014, antara jam 8 hingga 11.30 malam waktu lokal, serangan udara AS berhasil menghancurkan empat pos pemeriksaan ISIL yang dirancang untuk mencegah orang-orang Yazidi melarikan diri ke utara. Lalu, pada 12 Agustus 2014, Pemerintah AS memberikan dukungan udara bagi pasukan Kurdi untuk menghancurkan posisi mortir ISIL dan membantu Yazidi melarikan diri ke utara Gunung Sinjar. Kemudian, pada tanggal 13 Agustus 2014, serangan udara diberikan oleh AS yang mengarah kepada truk ISIL di dekat pos pemeriksaan di sebelah barat Sinjar. Dalam melancarkan serangan ini, AS melakukan sekitar 50 hingga 60 penerbangan setiap harinya (Jones, 2015).

Selain itu, AS juga membentuk sebuah koalisi yang bernama Global Coalition to Defeat ISIL/Daesh yang juga ikut andil dalam melindungi Yazidi dari serangan ISIL. Koalisi ini dideklarasikan pada 10 September 2014 oleh Presiden Obama. Kemudian, pada 24 September 2014, AS di dalam Majelis Umum PBB kembali menegaskan bahwa AS siap untuk bekerja dengan Koalisi untuk membongkar jaringan ISIL dan menyerukan dunia untuk bergabung. Dua minggu kemudian, sebanyak 40 negara menyatakan bergabung dalam koalisi Amerika tersebut. Lalu, Gedung Putih menunjuk Jenderal John Allen menjadi Utusan Khusus Presiden untuk Koalisi dan Wakil Asisten Sekretaris Negara Brett McGurk sebagai wakilnya.

Berdasarkan kerangka R2P, intervensi yang dilakukan oleh Amerika dapat dipandang sejalan dengan Pasal 51 Piagam PBB mengenai self-defence atau pertahanan diri sendiri. Di dalam pasal itu disebutkan bahwa suatu negara dapat meminta dukungan dari pihak lain, yaitu dari komunitas internasional untuk membantunya mengatasi suatu krisis. Hal inilah yang terjadi di Irak di mana terdapat genosida yang menimpa Yazidi di Sinjar, sehingga pemerintah Irak memiliki hak untuk membela negaranya sendiri, baik secara individu maupun secara kolektif dari adanya serangan bersenjata ISIL. Dalam kasus ini, Irak memilih untuk membela negaranya dan melindungi populasi Yazidi secara bersama-sama, atau disebut sebagai collective self-defence bersama dengan AS sebagai bagian dari komunitas internasional.

Self-defence ini, baik individu maupun koloketif dapat dilakukan dengan satu syarat, yaitu Irak harus memberitakan self-defence ini kepada DK PBB, yang mana dalam kasus ini Irak telah mengirimkan surat kepada DK PBB pada September 2014 yang menyatakan bahwa: 
"In accordance with international law and the relevant bilateral and multilateral agreements, and with due regard for complete national sovereignty and the Constitution, we have requested the United States of America to lead international efforts to strike ISIL sites and military strongholds, with our express consent." (Bannelier-Christakis, 2016)

Dengan surat tersebut, Pemerintah Irak menegaskan bahwa pihaknya meminta AS untuk memimpin upaya internasional untuk menyerang wilayah-wilayah ISIL yang ada di Irak, yang dilakukan sesuai dengan hukum internasional dan perjanjian bilateral dan multilateral yang disetujui oleh Irak. Selain itu, surat tersebut juga menyatakan bahwa pemerintah telah setuju atau mengekspresikan consent-nya atas penggunaan kekerasan yang dilakukan oleh AS beserta koalisinya di wilayah teritorinya. Keberadaan persetujuan ini menjadi dasar atas intervensi militer yang dilakukan oleh Amerika. Hal ini juga sesuai dengan Pasal 20 ARSIWA 2001 yang berbunyi:

"Valid consent by a State to the commission of a given act by another State precludes the wrongfulness of that act in relation to the former State to the extent that the act remains within the limits of that consent." (United Nations, 2001)

Berdasarkan pasal tersebut, penggunaan kekerasan dibolehkan berdasarkan kepada consent atau persetujuan negara tempat dilangsungkannya operasi militer, selama sesuai dengan batasan-batasan yang terlah disepakati oleh kedua belah pihak.

\section{Collateral Damage}

Telaah kritis terhadap intervensi militer AS dalam kerangka R2P dapat dilakukan dengan merujuk kepada klausul proportional means, yang berarti bahwa serangan dilakukan dengan intensitas minimum sejauh yang diperlukan untuk menyelamatkan kemanusiaan yang menjadi target; serangan juga harus difokuskan dan ditargetkan secara sempit, alih-alih perang dalam skala besar (more narrowly focused and targeted than all out warfighting) (ICISS, 2001: 37).

Selama 1 tahun (Agustus 2014-Agustus 2015), AS telah melakukan 5700 serangan bom terhadap target-target ISIL di Irak dan Suriah. Dalam serangan ini, terjadi collateral damage atau dampak sampingan, di mana ada ratusan warga sipil tewas. Dalam laporan yang dirilis oleh Airwars, sebuah proyek investigasi yang dilakukan 
sejumlah jurnalis independen, dalam serangan AS tersebut minimalnya 459 warga sipil tewas, termasuk di antaranya 100 lebih anak-anak (Ross, 2015).

Di antara serangan paling berdarah terjadi pada 3 Juni 2015 di mana 70 warga sipil tewas akibat dibombardir AS. Dalam jumpa pers setelah serangan itu, juru bicara Koalisi menyatakan, "Jika ada korban yang tidak sengaja, maka yang bertanggung jawab adalah ISIL." Kejadian lainnya adalah serangan tanggal 28 Desember 2014 di mana AS menyerang fasilitas ISIL yang ternyata adalah penjara di mana warga sipil yang menjadi tawanan ISIL masih ada di dalamnya. Minimalnya ada 58 warga sipil yang tewas dalam serangan itu (Ross, 2015).

Dari laporan ini, dapat terlihat bahwa klausul proportional means dalam R2P tidak dilakukan AS dan Koalisi secara maksimal.

\section{Responsibility to Rebuild}

Responsibility to rebuild merupakan tahap ketiga dari R2P, berkaitan dengan upaya pemenuhan kewajiban komunitas internasional setelah dilakukannya intervensi militer, yang terdiri dari peace building, security, justice and reconciliation, dan development. Dalam kasus Yazidi, responsibility to rebuild antara lain dilakukan oleh badan PBB yang menangani pengungsi, yaitu UNHCR. Upaya pemberian keamanan kepada pengungsi Yazidi, antara lain dilakukan dengan cara memberikan transportasi bagi kaum Yazidi dari perbatasan ke Newroz atas permintaan dari pengelola kamp lokal dan pengungsi itu sendiri. Pada saat itu, setidaknya terdapat 15.000 orang Yazidi yang mengungsi di Kamp Newroz dan ratusan orang lainnya tinggal di desa-desa atau kota-kota dekat Qahtaniyyeh dan Ras Al Ain. Berkaitan dengan hal ini, UNHCR kemudian bekerja sama dengan UN Response di Suriah dan membentuk sebuah misi bersama PBB dengan World Food Programme dan UN Children's Fund untuk menyediakan tempat berlindung dan barang-barang rumah tangga, makanan siap saji, biskut kaya energi, pakaian musim panas anak-anak, dan sabun (Sidky dan Rummery, 2014).

UNHCR juga turut membantu dalam mengusahakan pemindahan atau penempatan pengungsi Yazidi ke luar negeri. UNHCR dalam hal ini bekerja sama dengan Jerman, Australia, dan Kanada. Dengan pemerintah Jerman, khususnya dengan negara bagian Baden-Württemberg, UNHCR telah mendorong kesepakatan dimana Jerman mengambil keputusan pada Oktober 2014 untuk membawa 1.000 wanita dan anak-anak Yazidi untuk dirawat di Jerman dengan visa kemanusiaan khusus dengan anggaran sebesar 95 juta Euro. Dalam program ini, seribu wanita 
dan anak-anak tersebut menerima perawatan medis termasuk terapi yang dilakukan di bawah program dari Federal Republic of Germany (Human Right Council, 2016). UNHCR bermitra dengan Pemerintah Australia untuk menyediakan pemukiman bagi 6.501 pengungsi Yazidi, yang ditempatkan di wilayah New South Wales dan 250 orang lainnya ditempatkan di Wagga Wagga. Dengan program ini, pengungsi Yazidi mendapat jaminan perlindungan terhadap pemulangan (refoulement) sehingga berhak untuk mendapatkan hak sipil, politik, sosial, ekonomi, dan budaya yang sama seperti warga lokal. Sedangkan dengan pemerintah Kanada, UNHCR berhasil mendorong kesekapatan untuk membawa pengungsi Yazidi ke Kanada. Pada 21 Februari 2017, Kanada mengumumkan akan memberikan bantuan kepada 1.200 pengungsi Yazidi melalui program Bantuan Penanggulangan Darurat Pemerintah, yang akan memprioritaskan perempuan Yazidi yang rentan, dan anak-anak serta keluarganya (Cinthya, 2017).

Responsibility to rebuild yang dilakukan oleh UNHCR ini berfokus kepada pemberian keamanan (security) kepada para pengungsi komunitas Yazidi. Respon UNHCR dalam kasus pengungsian ini berupa pemberian bantuan, transportasi, hingga proses resettlement atau pemukiman kembali. Pentingnya perlakuan bagi pengungsi sebagai bagian dari responsibility to rebuild ini tertuang dalam Laporan Sekjen tahun 1998 mengenai The Cause of Conflict and the Promotion of Durable Peace and Sustainable Development in Africa, yaitu sebagai berikut.

"Societies which have emerged from conflict have special needs. To avoid a return to conflict while laying a solid foundation for development, emphasis must be placed on critical priorities such as ... ensuring the safe, smooth, and eary repatriation and resettlement of refugees and displaced persons ..." (ICISS, 2001)

Berdasarkan deskripsi tersebut, dapat dilihat bahwa perlindungan bagi pengungsi merupakan salah satu prioritas penting yang harus dilakukan untuk mencegah kembalinya konflik. Perlindungan itu repatriasi dan pemukiman kembali pengungsi atau orang yang terlantar akibat konflik. Karena kondisi di kampung halaman kaum Yazidi (Sinjar) masih belum aman, resettlement yang dilakukan adalah dengan mengirim mereka ke negara-negara maju yang bersedia menampung mereka agar mereka mendapatkan kehidupan yang lebih baik.

\section{Simpulan}

Pada 3 Agustus 2014, Islamic State of Iraq and the Levant (ISIL) melancarkan serangan yang ditujukan kepada populasi Yazidi di wilayah Sinjar, Irak. Penyerangan 
yang dilakukan oleh ISIL ini kemudian diyakini sebagai genosida dengan merujuk kepada Pasal II Konvensi Genosida 1948 dan Pasal 6 Statuta Roma, yang mendefinisikan genosida sebagai segala tindakan yang dilakukan dengan niat untuk menghancurkan, seluruh atau sebagian, kelompok bangsa, etnis, ras, atau agama. Segala hal yang dilakukan oleh ISIL selama penyerangan ini diyakini memiliki intensi khusus untuk menghancurkan populasi Yazidi, melalui pembunuhan massal, pemindahan agama secara paksa, kejahatan seksual, perbudakan seksual, kerja paksa, dan tindakan keji lainnya.

Dari 3 tahap R2P, yaitu responsibility to prevent, responsibility to react, dan responsibility to rebuild, komunitas internasional tidak berhasil melakukannya. Setelah serangan ISIL terjadi, pemerintah Irak memiliki tanggung jawab untuk melindungi populasi Yazidi dari serangan tersebut. Namun karena pemerintah tidak mampu melakukannya, maka prinsip non-intervensi diberikan kepada komunitas internasional. Dengan kata lain, komunitas internasional mendapatkan hak untuk melakukan intervensi demi melindungi warga Yazidi. Atas dasar ini, AS melakukan intervensi militer, atau tahapan responsible to react dalam kerangka R2P. Selanjutnya, responsibility to rebuild juga harus dilakukan oleh komunitas internasional dan hal ini secara terbatas sudah dilakukan melalui upaya resettlement sebagian pengungsi Yazidi ke Jerman, Australia, dan Kanada.

Intervensi militer AS ke Irak untuk menyerang ISIL dilakukan dalam kerangka responsibility to react. Intervensi itu dapat dipandang sejalan dengan Pasal 51 Piagam PBB yang mengatur tentang self-defence atau pertahanan diri sendiri, di mana intervensi militer yang dilakukan oleh AS dianggap sebagai sebuah bentuk pertahanan diri kolektif atau collective self-defence di hadapan serangan ISIL. Selain itu, merujuk kepada Pasal 20 ARSIWA, disebutkan bahwa intervensi militer atau use of force dapat dijustifikasi jika negara target setuju dengan adanya intervensi tersebut dan dalam kasus ini, Irak telah memberikan persetujuannya. Namun demikian, dalam pelaksanaannya, ada klausul proportional means dalam R2P yang tidak dilakukan AS dan Koalisi secara maksimal sehingga menimbulkan korban jiwa dari kalangan sipil.

\section{Daftar Pustaka}

Bannelier-Christakis, Karine. (2016). Military Intervention against ISIL in Iraq, Syria and Libya, and the Legal Basis of Consent. Leiden Journal of Interntaional Law, 29 ( 3) 743-775. 
Breau, Susan. (2016). The Responsibility to Protect in International Law. New York: Routledge.

Cinthya, Megah. 2017. "Peran United Nations High Commissioner for Refugees (UNHCR) dalam Menangani Pengungsi Yazidi di Irak (2014-2017)." Jom FISIP Volume 4 No.2 1-15.

Human Rights Council. (2016). "They came to destroy": ISIS Crimes Against the Yazidis. Geneva: Human Rights Council.

ICISS. (2001). The Responsibility to Protect: Report of the International Commission on Intervention and State Sovereignty. Ottawa: International Development Research Centre.

International Criminal Court. (2011). Rome Statute of the International Criminal Court. The Hague: International Criminal Court.

Jones, Trevor. (2015). "Humanitarian Intervention at Mt. Sinjar, Iraq: A Complex Adaptive System Analysis." Electronic Theses and Dissertations 1-98.

Kizilhan, Jan Ilhan. (2017). The Yazidi-Religion, Culture and Trauma. Scientific Research Publishing Inc, 7, 333-339.

Mitrani, M. (2017). The Discursive Construction of the International Community: Evidence from the United Nations General Assembly. KFG Working Paper Series, 78, 1-30.

Muhdhor, A. (2017). Reasoning of Takfirism Assumption. Jurnal ICMES, 1(2), 166-186.

OHCHR \& UNAMI. (2014). Report on the Protection of Civilians in Armed Conflict in Iraq: 6 July - 10 September 2014. Geneva: OHCHR \& UNAMI.

Ross, A. (2015). Hundreds of civilians killed in US-led air strikes on Isis targets - report. The Guardian, [online]. Dalam: https://www.theguardian.com/world/2015/ aug/03/us-led-air-strikes-on-isis-targets-killed-more-than-450-civilians-report [Diakses 5 Desember 2019].

Sidky, M. dan Rummery, A. 2014. UNHCR steps up aid as Yazidis stream into Syria from Iraq's Mount Sinjar. UNHCR [online]. Dalam: https://www.unhcr.org/news/ latest/2014/8/53ecb7a29/unhcr-steps-aid-yazidis-stream-syria-iraqs-mountsinjar.html [Diakses 5 Desember 2019] 
Sliney, S. A. (2015). Right to Act: United States Legal Basis Under the Law of Armed Conflict to Pursue the Islamic State in Syria. University of Miami National Security \& Armed Conflict. Law Review, 6. 1-23.

Smith, Lieutenant Colonel Mark. (2017). Show and awe? An Examination of the terrorist group ISIL and its future prospects. Australian Defence Force Journal, (202), 45-52.

Theglobalcoalition.org. (website resmi Global Coalition Against Daesh).

United Nations. (2001). Responsibility of States for Internationally Wrongful Acts. [online] Dalam: https://legal.un.org/ilc/texts/instruments/english/draft_ articles/9_6_2001.pdf. [Diakses 3 Desember 2019].

United Nations. Charter of the United Nations and the Statute of the International Court of Justice. New York: United Nations Publications.

Webb, Amber. (2018). "In the Aftermath of Genocide: Report on the Status of Sinjar." Nadia's Initiative. [online]. Dalam: www.nadiasinitiative.org. [Diakses 3 Desember 2019].

Zoonen, Dave van, dan Khogir Wirya. (2017). "The Yazidis: Perception of Reconciliation and Conflict." Middle East Research Institute. [online] Dalam: http://www.meri-k. org/publication/the-yazidisperceptions-of-reconciliation-and-conflict/ [Diakses 3 Desember 2019]. 